\title{
CARACTERISTICAS DEL DESOVE DE CHURO, Pomacea maculata EN AMBIENTE CONTROLADO
}

\author{
Fernando Alcántara Bocanegra * \\ Nixon Nakagawa Valverde* \\ E Ivira Zamora Perea*
}

\section{RESUMEN}

Se reportan las características de los desoves de "churo", Pomacea maculata, en acuarios de vidrio en I quitos-Perú.

Se utilizaron seis acuarios de vidrio de $70 \times 40 \times 40 \mathrm{~cm}$. con un tirante de agua de $15 \mathrm{~cm}$. En cada acuario se colocaron cuatro "churos" adultos, proporcionándose alimento peletizado con un tenor de 30\% de proteina total y además hierbas acuáticas: "putu-putu", Eichornia crassipes, "lenteja de agua", Salvinia auriculata y "huama", Pistia stratiotes.

L a oviposición se realizó en las paredes internas de los acuarios a una altura de 15 a $30 \mathrm{~cm}$ sobre el nivel del agua.

Los desoves presentan una amplia variabilidad, tanto en longitud, como en ancho y espesor (coeficiente variabilidad (c.v) = 15 a $20 \%$ ).

El desarrollo ontogénico ocurre entre los 12 y 16 días, con una media de 14 días, obteniéndose entre 77 y 483 crías por desove, con un peso individual de 0,028 gramos.

EI número de crías representa aproximadamente del 44 al $50 \%$ de los huevos en cada puesta.

Palabras clave: "churo", Pomacea maculata, número de crías por desove.

* Investigadores del Instituto de Investigaciones de la A mazonía Peruana(IIAP). 


\section{INTRODUCCION}

El "churo", Pomacea maculata es un Gasterópodo oriundo de la A mazonía (PAIN, 1960), que está despertando interés para el cultivo, con fines de alimentación. Sin embargo, los parámetros productivos no están bien conocidos.

Villacorta (1976), realizó observaciones en el ambiente natural y en ambiente controlado, reportando que el desarrollo embriológico es de 13 a 19 días.

De otro lado, Mayta (1978), realizó estudios sobre biología de la especie en ambiente controlado en la costa peruana, señalando que la eclosión se produce entre 13 y 39 días, con un promedio de 25 días.

Este trabajo se realizó con la finalidad de comprobar las características del desove del "churo" y el número de crías por desove, en ambiente controlado, en la A mazonía.

\section{MATERIAL Y METODOS}

Se utilizaron seis acuarios de vidrio de $70 \times 40 \times 40 \mathrm{~cm}$ con un tirante de agua de $15 \mathrm{~cm}$. En cada acuario se colocaron seis "churos" adultos, con un peso promedio de $80 \mathrm{~g}$.

Los "churos" fueron alimentados con pelets con un tenor de $30 \%$ de proteína total, cuyos insumos fueron: harina de pescado, torta de soya, harina de maíz y polvillo de arroz. El alimento se proporcionó a razón de $3 \mathrm{~g} /$ día por acuario. A dicionalmente, en cada recipiente se colocaron plantas acuáticas tales como: "putu-putu", Eichornia crassipes, "lenteja de agua", Salvinia auriculata y "huama", Pistia stratiotes.

Semanalmente se efectuó la limpieza del acuario para eliminar la materia orgánica de fondo.

Al detectarse los desoves se efectuaron seguimientos individuales. 


\section{RESULTADOS Y DISCUSION}

Como se puede apreciar en la tabla 1, los desoves de "churo" se caracterizan por presentar una amplia variabilidad tanto en longitud, como en ancho y espesor (c.v $=15$ a 20\%). Sin embargo, el período necesario para el desarrollo ontogénico es más o menos homogéneo y está comprendido entre 12 a 16 días, con una media de 14 días (c.v $=5.78 \%$ ).

Los desoves se efectuaron durante la noche en las paredes internas del acuario, a una altura comprendida entre 15 a $25 \mathrm{~cm}$ sobre el nivel del agua del recipiente.

Al momento de la puesta, los huevos presentaron un color verde claro intenso que se fue tornando blanquesino con el transcurso de los días, al aproximarse la eclosión.

Relacionando el número de crías y el número de huevos por desove, en base a una muestra del $10 \%$ de desoves, se observó que las crías representan del 44 al $50 \%$ del número de huevos.

A dicionalmente se observó que en cada puesta se presenta un escaso número de huevos con desarrollo ontogénico tardío, que sobrepasa el promedio de 14 días para la eclosión.

De otro lado se observó que al producirse la eclosión los churitos van cayendo al agua en forma individual 0 en grupos y en contacto con el agua, algunas veces se sumergen hasta el fondo del acuario y otras quedan flotando en superficie por unos minutos, para luego descender al fondo. 
TABLA 1. Características de los desoves de "churo", Pomacea maculata, en ambiente controlado.

\begin{tabular}{|c|c|c|c|c|c|c|c|}
\hline № & $\begin{array}{l}\text { Long. } \\
\text { (mm) }\end{array}$ & $\begin{array}{l}\text { Ancho } \\
\text { (mm) }\end{array}$ & $\begin{array}{c}\text { E spesor } \\
\text { (mm) }\end{array}$ & $\begin{array}{l}\text { E clos. } \\
\text { (días) }\end{array}$ & $\begin{array}{l}\text { № de } \\
\text { (crías) }\end{array}$ & $\begin{array}{c}\text { Pes. tot } \\
\text { (g) }\end{array}$ & $\begin{array}{c}\text { Peso } \\
\text { medio (g) }\end{array}$ \\
\hline 1 & 53.30 & 22.45 & 16.15 & 13 & 464 & 7.5 & 0.016 \\
\hline 2 & 57.65 & 27.45 & 16.50 & 14 & 483 & 10.0 & 0.021 \\
\hline 3 & 59.35 & 27.25 & 17.20 & 14 & 462 & 10.5 & 0.022 \\
\hline 4 & 41.70 & 21.20 & 19.25 & 14 & 139 & 5.6 & 0.040 \\
\hline 5 & 54.60 & 30.50 & 13.45 & 14 & 206 & 8.5 & 0.041 \\
\hline 6 & 63.95 & 16.00 & 27.45 & 14 & 454 & 13.0 & 0.028 \\
\hline 7 & 46.00 & 46.25 & 20.00 & 14 & 442 & 11.3 & 0.025 \\
\hline 8 & 59.35 & 28.35 & 18.35 & 14 & 394 & 19.4 & 0.049 \\
\hline 9 & 51.65 & 25.45 & 17.95 & 14 & 291 & 10.0 & 0.034 \\
\hline 10 & 63.70 & 25.90 & 20.40 & 14 & 300 & 12.0 & 0.040 \\
\hline 11 & 49.00 & 33.60 & 21.00 & 14 & 380 & 12.0 & 0.031 \\
\hline 12 & 46.45 & 21.30 & 17.55 & 14 & 310 & 12.3 & 0.039 \\
\hline 13 & 54.25 & 27.30 & 14.55 & 14 & 260 & 7.0 & 0.026 \\
\hline 14 & 67.20 & 30.55 & 18.20 & 13 & 594 & 13.0 & 0.021 \\
\hline 15 & 35.45 & 26.95 & 20.40 & 14 & 290 & 8.0 & 0.027 \\
\hline 16 & 41.65 & 21.40 & 21.50 & 15 & 77 & 2.5 & 0.032 \\
\hline 17 & 47.00 & 30.05 & 17.40 & 13 & 437 & 19.0 & 0.043 \\
\hline 18 & 52.90 & 32.75 & 16.25 & 12 & 370 & 9.0 & 0.024 \\
\hline 19 & 58.00 & 26.20 & 13.00 & 14 & 271 & 8.0 & 0.029 \\
\hline 20 & 67.00 & 25.95 & 15.00 & 13 & 390 & 8.0 & 0.020 \\
\hline 21 & 50.80 & 29.30 & 18.50 & 13 & 420 & 8.5 & 0.020 \\
\hline 22 & 58.05 & 21.30 & 14.70 & 13 & 460 & 10.5 & 0.022 \\
\hline 23 & 57.90 & 25.15 & 16.20 & 16 & 350 & 5.2 & 0.014 \\
\hline 24 & 112.90 & 25.00 & 11.50 & 15 & 356 & 5.8 & 0.016 \\
\hline$x$ & 53.78 & 26.98 & 17.60 & 13.83 & 358 & 9.85 & 0.028 \\
\hline $\mathrm{S}$ & 8.11 & 5.67 & 3.27 & 0.80 & 114 & 3.82 & 0.009 \\
\hline máx. & 112.90 & 46.25 & 27.45 & 16.00 & 594 & 19.40 & 0.049 \\
\hline $\min$. & 35.45 & 21.20 & 11.50 & 12.00 & 77 & 2.50 & 0.016 \\
\hline
\end{tabular}




\section{BIBLIOGRAFIA}

MAYTA L., RAUL. 1978. Estudio sobre la biología del "churo" (Pomacea maculata, Ampullaridae, Gasteropoda: Perry) en el laboratorio. UNA: A nales Científicos UNA, XVI (1-4): 11-14.

PAIN, T. 1960. Pomacea (Ampullaridae) of the Amazon River System.En: J ournal of Conchology. Vol. 24 No 12.

VILLACORTA C., MARLE. 1976. Algunas consideraciones del "churo", Pomacea maculata, Perry. Tesis para optar el título profesional de Biólogo. Iquitos: Universidad Nacional de la Amazonía Peruana. Programa A cadémico de Biomédicas. 